CHALLENGING MIDWIFERY CARE, CHALLENGING MIDWIVES AND CHALLENGING THE SYSTEM

Challenging midwifery care

Author: Caroline SE Homer, PhD, RM

Institution: Centre for Midwifery and Family Health, Faculty of Nursing, Midwifery and Health, University of Technology Sydney

Corresponding author:

Professor Caroline Homer

Centre for Midwifery and Family Health

Faculty of Nursing, Midwifery and Health

University of Technology Sydney

PO Box 123

Broadway NSW 2007

Tel 0295142977

Fax: 0295141678

Emails: Caroline.homer@uts.edu.au 


\section{Abstract}

The purpose of this paper is to generate debate and discussion about the state of midwifery services in Australia today. While numerous reports have been published that highlight what women want in maternity care, widespread change has not occurred.

This paper presents the story of Alice (a real woman with a fictitious name). Alice's story highlights the challenges that women face in dealing with a system that is often inflexible. While the health systems, and those who work within them, usually have the best intentions to try to provide the type of care that women want, they are not always successful.

The paper summarises the evidence and support for models of continuity of midwifery care and outlines a series of strategies to ensure that change can occur. Finally, the paper challenges all midwives to work towards widespread, system-level change in Australian maternity services.

\section{MeSH keywords}

Midwifery; Continuity of Care; Maternity Hospitals; Health care systems 


\title{
CHALLENGING MIDWIFERY CARE, CHALLENGING MIDWIVES AND CHALLENGING THE SYSTEM
}

\section{Introduction}

Recently, at a social function, I met a woman, Alice, and her four month old baby, Nicholas. Last time I saw her was prior to her pregnancy. She knew I was a midwife and after lunch she told me about her childbearing experience.

This paper presents her story (with her permission) from her recollection of the events. Alice's story highlights the challenges that women face in dealing with a system that is often inflexible. The paper summarises the evidence for models of continuity of midwifery care and outlines a series of strategies to ensure that change can occur. Finally, the paper challenges all midwives to work towards widespread, system-level change in Australian maternity services.

\begin{abstract}
Alice's story
The woman, I will call her Alice (all the names have been changed and the location is anonymous to protect confidentiality) is a professional women in her early thirties. Her partner is John and this is their first baby. Alice is wise and sensible with a family who clearly understands about midwifery care. Her sister has had two homebirths. Alice did not want a homebirth but wanted midwifery care, or more specifically, continuity of midwifery care and carer.
\end{abstract}

Alice booked in at her local hospital, which is a large teaching hospital with a number of options of care. She booked in with the model of care which offered continuity of midwifery care through pregnancy, labour and birth and the postnatal period. The model of care was offered in a homelike environment, similar to a birth centre. She was given the impression she would be cared for by a small number of midwives and would be able to develop a relationship with them through the antenatal period. This relationship was what she wanted. Alice and John, however, had seven antenatal visits through her healthy pregnancy with six different midwives.

Alice went into labour at term and, after 20 hours of contractions, she and John came into the birth centre area. The story Alice told sounded as if she had a long latent phase of labour, with painful, strong, increasingly frequent, but irregular contractions and backache that meant she was unable to sleep. She was given a pethidine injection and some sleeping tablets but only got an hours' sleep and felt even more tired. Over the course of the next 48 hours, Alice was continually told that she was "not in labour" that nothing was happening, and that nothing could be done. She says she felt that her labour different to what the midwives felt was 'the normal labours that they saw' and therefore she was not deserving of attention. The midwives said "if you lived closer we would have sent you home” which made her feel even less deserving of care or attention. After some time, Alice was moved out of the birth centre and sent to the antenatal ward because, she was told, someone was coming who was "in proper labour". At no time did any of the five different midwives she saw talk to her about what was going on, give likely explanations (like an occipto-posterior position) or make her or John feel part of any decision-making process. 
Alice talked of feeling 'abandoned' throughout this time. She says that she felt her labour did not fit the pattern that the midwives expected. She sensed that her labour was not following the 'normal expected course' and therefore the midwives did not know what to do with her. Out on the antenatal ward, the feeling of abandonment continued and she was uncomfortable and distressed in such a public space. A student midwife came and checked her every few hours. There was little information, explanation or support provided to Alice or John during this time. She also feels that there was no validation of her experience; of what she was going through and certainly no help to get through it.

Finally, after many hours, Alice and John begged for pain relief and they were transferred to the labour ward area where she met another group of midwives. Alice and John were both exhausted and distressed. Alice describes how relieved she felt when a midwife listened to her and understood her need for sleep and pain relief. The midwife and obstetrician in the labour ward recognised that this labour needed assistance. An epidural was inserted and a syntocinon infusion commenced. Finally, Alice gave birth, assisted by forceps, to a baby boy. Alice estimates that by the time of Nicholas' birth she had had three hours sleep in 72 hours and felt debilitated and weary. She says, that by the time he was born, she had almost totally forgotten that she was even having a baby, saying, "I was just too tired."

After the birth, Alice was transferred to the postnatal ward where she spent three nights. Again, she was attended by a totally new group of midwives. She went home on day four and three midwives from the hospital visited her at home over the next 10 days. One midwife was excellent, providing assistance through breastfeeding difficulties including an episode of mastitis and a breast abscess. Alice felt that part of the reason that she had difficulties with breastfeeding was that she was so exhausted after the birth that she did not have the ability to follow the advice she was given. She could not sleep in hospital due to the constant interruptions throughout the day, from the TV rental person to the photographer, physiotherapist, hearing tester, newspaper delivery and catering as well as the midwives and obstetric staff. She felt she needed to get home to get some sleep and rest.

Alice estimated that she was cared for by at least 30 different midwives through her pregnancy, labour and birth and postnatal period. This, from her perspective, was too many. She wanted, above all, consistent faces, consistent information and to be heard.

Alice is thinking about her next pregnancy (even though she is very reluctant to do it all again) and the options that she has. She identified that continuity of carer from a private midwife with visiting rights would be ideal. These, however, are rare. A model where she saw only two or three midwives in a caseload practice would be ideal but again, these are not widespread in her region. Her only option to ensure some measure of continuity of caregiver is a private obstetrician. It seemed, in talking with Alice, that this was not her preference but was looking like her only viable option to ensure continuity of caregiver.

\section{Challenging models of midwifery care}

Alice's story highlights the need for models of care that provide continuity of midwifery caregiver, in reality not only rhetoric. It is likely that her experience would 
have been less traumatic and fragmented if she experienced care from a small number of known midwives who followed her through her childbearing experience.

Many of us have been campaigning for some years for midwifery models of care that provide continuity of caregiver. It is heartening to see that this has happened in many places and planned in others. Perhaps we also need to admit that, at times, our midwifery models of care are not providing the level of continuity of caregiver that women need or want. The rhetoric that sometimes says "we have lots of options of care including midwifery models" needs to be unpacked to uncover the reality. Alice was cared for within a midwifery model of care but was it any better than a mainstream option she would have received 10 years ago? It is likely that it was better than many of the standard options that are available but this is more of an indication about how dire the situation was a decade ago, rather than how well we are doing now.

Changing the way midwives work so that they can develop meaningful relationships with woman seems simple on one level. Changing the system so that women's needs, rather than the needs of the institution, are paramount is crucial. Such change however requires a shift in locus of control from the institution to the woman. This is a shift that has an abundance of evidence to support it but sometimes, a lack of capacity or will to implement on a widespread level.

\section{The evidence for change}

There is plenty of evidence from research, reports and policy directives that indicate that we should be providing woman centred care with continuity of caregiver as a central tenet. The evidence goes back many years and is, at times, controversial ${ }^{1}$. The Shearman Report in NSW, published in 1989, recommended that widespread systemic changes needed to occur ${ }^{2}$. More recent policy directives in NSW have continued this approach ${ }^{34}$. Other states have undertaken similar reviews of maternity services with many comparable recommendations ${ }^{5-7}$. The National Maternity Action Plan (NMAP), which was launched in 2002, called on governments to give each Australian woman the choice of having her own midwife throughout pregnancy, labour and birth, and for the important first weeks of life with a new baby. NMAP supported community midwifery where women can choose to give birth in hospital labour wards, birth centres or at home, with their own midwife caring for them from early in pregnancy till after the birth of their baby ${ }^{8}$.

The first randomised controlled trials of continuity of midwifery care date back to the late $1980 \mathrm{~s}^{9}$ and many have followed including a number of Australian trials ${ }^{10-15}$. Other research has demonstrated the benefits of one-to-one ${ }^{16}$ and caseload models of care ${ }^{17}$. Caseload models have also been shown to be beneficial for midwives, reducing burnout and improving retention ${ }^{1718}$. There are calls to make caseload practice the 'gold standard' model of care for women in the UK ${ }^{19}$.

Despite all the evidence, the widespread movement towards models that provide continuity of midwifery carer within the public health system has been limited in Australia. There are small numbers of caseload practices and team midwifery models in most states and territories. However, the total proportion of women who receive continuity of midwifery carer is small. Some centres have made excellent progress in moving to systems where continuity of midwifery carer is available to the majority of 
women but these are in the minority. For example, the Women's and Children's Hospital in Adelaide has a caseload midwifery model for around 1000 women per year ${ }^{20}$. The caseload models at Ryde Hospital in Sydney ${ }^{21} 22$; the Birth Centre at St George Hospital in Sydney ${ }^{23}$; the Community Midwifery Program in Fremantle in Western Australia ${ }^{24}$; and, the Northern Women's Community Midwifery Program in Adelaide ${ }^{25}$ are also excellent examples of where considerable efforts have been made to ensure women have continuity of caregiver.

Team midwifery has also been instituted in a number of settings however, there is considerable dispute about what constitutes a small team of midwives. The randomised controlled trials on team midwifery showed positive outcomes with teams of six to eight midwives ${ }^{911-14}$. In many settings in Australia, teams are now made up of 20 or more midwives who work rotating shifts through the maternity unit. It is hard to see how any amount of continuity of carer is possible with teams this size. It is equally difficult to see how the outcomes that were demonstrated in the team midwifery studies will be replicated with teams that consist of 20 midwives.

Rural and remote settings are also struggling to develop models of care that provide continuity of caregiver and utilise midwives appropriately. The barriers faced in these areas are slightly different and include a monopoly on antenatal care by some local general practitioners, a shortage of midwives and the need for midwives to also work as nurses. The National Rural Health Alliance's Birthing in the Bush project recognises the need to develop and sustain models of maternity care in rural and remote areas and is currently developing a position paper on a proposed framework for service provision ${ }^{26}$.

New educational models for midwifery provide additional evidence for change. A Bachelor of Midwifery program is now in place in three (soon to be four) states in Australia. This means that in future years, a proportion of midwifery graduates will no longer be registered nurses. If Australia follows the experience in New Zealand or the United Kingdom, it is likely that in 10 to 20 years, a majority of midwives will be educated in this way. This will have significant implications on the way maternity services are provided and will increase the impetus for midwifery-led models of care.

\section{Ways to progress}

Progress is clearly occurring but it is slow. Resistance to widespread change is still evident in many settings and from many quarters. Reasons for this includes workforce shortages; inflexible industrial arrangements; opposition from the medical profession; lack of appropriate funding models, reluctance by managers to institute new ways of working; lack of opportunity to practise across the full spectrum of maternity care; lack of prescribing rights; and, an inability to order routine tests ${ }^{28-30}$. The Review of Services Offered by Midwives ${ }^{31}$ recommended that changes be made to enable midwives to prescribe common drugs and order routine tests. This has again been reiterated in a recent paper on health workforce design and future planning ${ }^{32}$.

The Joint Committee for Maternity Services re-established by the Royal Australian and New Zealand College of Obstetricians and Gynaecologists (RANZCOG), has called for an Australian National Maternity Policy. Some of the elements of such a policy will include the provision of woman centred care that provides continuity during pregnancy, labour and birth and postnatally. The need to develop systems of 
care that will protect against burnout of care providers has also been recognised by this committee ${ }^{33}$.

Policy documents in a number of states and territories support models of midwifery care, including midwifery-led services ${ }^{334}$. It is essential that these positive moves are encouraged and supported and that we find ways around the barriers. Events in the media indicate that midwives are a force to be reckoned with knowledge, experience, wisdom and a determination to speak out ${ }^{35}$.

Developing strong alliances with consumer groups and professional organisations is an effective and important strategy to progress forward. Women in consumer groups, like Maternity Coalition, are highly skilled in political action and agitation. Their voices are often the ones that the politicians listen to as their local, state or federal government representative. Joining, or becoming more active in a professional midwifery association, for example, the Australian College of Midwives, is also a strategy to work towards collective action.

Collaboration with our medical colleagues is another strategy. Working together to ensure that systems are established and funded that ensure that midwives can work to their full scope of practice providing safe, high quality care. This requires a range of political and professional strategies and changes to the current funding arrangements 3637

Ensuring that there are midwives who can conceive of working in continuity of care models is an essential ingredient. Often, it is the newly graduated midwives who are our best advocates of midwifery models of care - it is what they have been educated to undertake. New graduates are a wonderful resource and should be included in these new models. They may need additional support, especially in the early days, but their energy, enthusiasm and commitment needs to be channelled into these models of care. It is likely that they will be receptive to new ways of working and to new models of service provision.

\section{Conclusion}

It is likely that there are a lot of women like Alice in Australia. It can be assumed that other women also want to be listened to by midwives who are interested in them as an individual, who remember them from visit to visit and with whom they can develop a trusting relationship. They want to feel cared for and to have their experience validated. They want us to communicate effectively and to provide consistent information that is based on evidence and best practice. They want to know their caregivers and see familiar faces throughout the antenatal, labour, birth and postnatal periods.

None of the things that the Alices and other childbearing women of Australia want are amazing nor should they be impossible to provide. They are what we as midwives are educated to provide; no matter where or how we work. It is our role to make the sharp edges of the system curved and ensure that women are supported through the tight and often confusing corners. Models of continuity of midwifery care are an ideal we should all work towards. In the meantime however, we can all work towards ensuring that all women receive the kind of care that they want and that they deserve. 


\section{Acknowledgements}

Thank you to 'Alice' for allowing her story to be told. Thank you also to my colleagues, Lin Lock and Suellen Allen, who provided advice on earlier versions of this manuscript. 


\section{References}

1. Green JM, Curtis P, Price H, Renfrew MJ. Continuing to care: The organisation of midwifery services in the UK. Hale: Books for Midwives Press, 1998.

2. NSW Health Department. Final Report of the Ministerial Task Force on Obstetric Services in NSW: The Shearman Report. State Health Publication No. (HSU) 89-007 ed. Sydney: NSW Department of Health, 1989.

3. NSW Health. Models of Maternity Service Provision. Sydney: NSW Department of Health, 2003.

4. NSW Health. A Framework for Managing the Quality of Health Services in NSW. State Health Publication No: (HPA) 990024 ed. Sydney: NSW Health Department, 2000.

5. Victorian Department of Health. Having a Baby in Victoria: Ministerial Review of Birthing Services in Victoria. Melbourne: Victorian Department of Health, 1990.

6. Department of Health Western Australia. Ministerial task force to review obstetric, gynaecological and neonatal services in Western Australia. Perth: Health Department of Western Australia, 1990.

7. Hirst C. ReBirthing: Report of the Review into Maternity Services in Queensland. Brisbane: Queensland Health, 2005.

8. Maternity Coalition. National Maternity Action Plan for the introduction of community midwifery services in urban and regional Australia. Canberra: Maternity Coalition, AIMS (Australia), Australian Society of Independent Midwives, Community Midwifery WA Inc, 2002.

9. Flint C, Poulengeris P, Grant A. The 'Know Your Midwife' scheme - a randomised trial of continuity of care by a team of midwives. Midwifery 1989;5(1):11-16.

10. Waldenström U, Brown S, McLachlan H, Forster D, Brennecke S. Does team midwifery care increase satisfaction with antenatal, intrapartum and postpartum care? A randomised controlled trial. Birth 2000;27(3):156-167.

11. Kenny P, Brodie P, Eckermann S, Hall J. Westmead Hospital Team Midwifery Project Evaluation: Final Report. Sydney, NSW: Westmead Hospital, 1994.

12. Rowley MJ, Hensley MJ, Brinsmead MW, Wlodarczyk JH. Continuity of care by a midwife team versus routine care during pregnancy and birth: a randomised trial. Medical Journal of Australia 1995;163(6):289-193.

13. Homer CSE, Davis GK, Brodie PM, Sheehan A, Barclay LM, Wills J, et al. Collaboration in maternity care: a randomised controlled trial comparing community-based continuity of care with standard care. British Journal of Obstetrics and Gynaecology 2001;108(1):16-22.

14. Biro MA, Waldenström U, Pannifex JH. Team midwifery in a tertiary level obstetric service: A randomised controlled trial. Birth 2000;27(3):168-173.

15. Waldenström U, MacLachlan H, Forster D, Brennecke S, Brown S. Team midwife care: maternal and infant outcomes. Australian and New Zealand Journal of Obstetrics and Gynaecology 2001;41(3):257-264.

16. McCourt C, Page L, Hewison J. Evaluation of One-to-One Midwifery: Women's responses to care. Birth: Issues in Perinatal Care and Education 1998;25(2):73-80.

17. Sandall J, Davies J, Warwick C. Evaluation of the Albany Midwifery Practice: Final Report March 2001. London: King's College, 2001.

18. Sandall J. Midwives' burnout and continuity of care. British Journal of Midwifery 1997;5(2):106-111. 
19. Lester A. The argument for caseload midwifery. MIDIRS Midwifery Digest 2005;15(1):27-30.

20. CYWHS. Midwifery Group Practice: An Evaluation of Clinical Effectiveness, Quality and Sustainability. Adelaide: Children, Youth and Women's Health Service, Women's and Children's Hospital, 2005.

21. Tracy S, Hartz D, Nicholl M, McCann Y, Latta D. An integrated service network in maternity - the implementation of a midwifery-led unit. Australian Health Review 2005;29(3):332-339.

22. Tracy S, Hartz D. The Quality Review of Ryde Midwifery Group Practice, September 2004 to October 2005: Final Report. Sydney: Northern Sydney and Central Coast Health, 2005.

23. Passant L, Homer C, Wills J. From student to midwife: the experiences of newly graduated midwives working in an innovative model of midwifery care. Australian Journal of Midwifery 2003;16(4):18-21.

24. Thiele B, Thorogood C. Community Based Midwifery Program in Fremantle WA. Fremantle: Centre for Research for Women (WA) and the Fremantle Community Midwives, 1997.

25. Church A, Nixon A. An Evaluation of the Northern Women's Community Midwifery Program. Adelaide: Department of Human Services, 2002.

26. NRHA. National Rural Health Alliance: Media Release - Make Every Mother and Child Count in rural and remote Australia: NRHA, 2005.

27. NRHA. Communique and Key Recommendations from the 8th National Rural Health Conference: National Rural Health Alliance, 2005.

28. Brodie P. Addressing the barriers to midwifery: Australian midwives speaking out. Journal of the Australian College of Midwives 2002;15(3):5-14.

29. Leap N, Barclay L, Sheehan A. Results of the Australian Midwifery Action Project Education Survey. Paper 2: Barriers to effective midwifery education as identified by midwifery course coordinators. Australian Midwifery Journal 2003;16(3):6-11.

30. Leap N. Identifying the practice component of Australian midwifery education programs: Results of the Australian Midwifery Action Project (AMAP) Education Survey. Australian Midwifery Journal 2002;15(3):15-23.

31. NHMRC. Review of services offered by midwives. Canberra: Commonwealth of Australia, 1998.

32. Duckett S. Health workforce design for the 21st century. Australian Health Review 2005;29(2):201-210.

33. Weaver E, Clark K, Vernon B. Obstetricians and midwives modus vivendi for current times. Medical Journal of Australia 2005;182(9):436-437.

34. Victorian Health. Future directions for Victoria's maternity services. Melbourne: Department of Human Services, Victoria, 2004.

35. Cresswell A. Midwife care gets seal of approval. The Weekend Australian (3/9/05) 2005;9.

36. Humphrey M. Editorial. Australian and New Zealand Journal of Obstetrics and Gynaecology 2006;46(1):1.

37. Homer C. Collaboration in maternity care. A response to 'what do I think of midwife-led units?' Australian and New Zealand Journal of Obstetrics and Gynaecology 2006;46:262. 